temperature without deteriorating. We therefore performed some simple experiments to assess this.

Twelve sera were taken, six known to be positive and six known to be negative to both antigens. The reagents were made up and distributed on the machine and the test was completed in the usual way. The apparatus was left standing for two hours and the procedure repeated using fresh samples of the same 12 sera. The results were identical even in two cases in which only a few cells remained. The procedure was repeated after a further two hours with identical results. The apparatus may thus be run continuously for at least three hours without any deterioration in the reagents, and there is a considerable safety margin. In that time, 540 specimens could be processed.

One could have devised automatic apparatus for distributing the patients' sera, adding the sensitized red blood cells and for reading the results. However, in view of the complication that would be introduced and the fact that the time taken to perform each of these stages manually is very small compared with the time taken to dispense the reagents, we decided to continue to perform these stages manually.

\section{FINAL COMMENTS}

We have demonstrated that the machine is a satisfactory aid in performing the serological diagnosis of syphilis. The apparatus is moderately cheap, many of the components are commercially available, and it does not suffer from the disadvantages of the AutoAnalyzer method. It is suitable for carrying out the procedures on up to at least 500 to 600 specimens per day, and in smaller laboratories, for which it is particularly suitable, pathologists might well be encouraged to store samples, thus effecting a considerable saving of time.

The basic principles of the apparatus could be used for a method of performing any complement-fixation technique. If the apparatus were modified to accommodate more reaction tubes, either by increasing the number of racks that could be attached to the turntable, which number is limited only by the size of turntable required, or by using a 'continuous-flow' mechanism operated by a chain, the apparatus could be used for very large batches of sera: in this case, more attention would have to be paid to the deterioration of reagents, and more exhaustive experiments than those reported here would have to be performed before the design was finalized.

I am greatly indebted to the Trustees of the Nuffield Foundation who financed the project, and to Professor R. E. O. Williams for his invaluable counsel. The technical assistance of S. Haskey and G. Dickerson is gratefully acknowledged.

\section{REFERENCES}

Pugh, V. W., and Gaze, R. W. T. (1965). Brit. J. vener. Dis., 41, 221. (1966). J. clin. Path., 19, 595.

Sequeira, P. J. L. (1964). Personal communication.

Taylor, C. E. D., Kershaw, J. W., and Heimer, G. V. (1968). J. clin. Path., 21, 521.

Trotman, R. E. (1967a). Ibid., 20, 770.

—_ (1967b). J. appl. Pneum., 6 No. 48, 9.

\section{Use of microplates for monolayer tissue cultures}

\author{
I. F. C. MCKENZIE ${ }^{1}$ AND P. J. MORRIS From the \\ University of Melbourne Departments of Medi- \\ cine and Surgery, The Royal Melbourne Hos- \\ pital, Victoria 3050, Australia
}

Monolayer cultures of cells are used extensively in research laboratories and for routine detection of viruses. One disadvantage of the technique is that large numbers of cells are required, and for quantitative experiments the use of sterile flasks becomes expensive. We describe the use of microplates for monolayer cultures, a technique enabling a large number of tests to be done with a small number of cells.

\section{METHODS}

THE PLATE The microplates are available commercially (Falcon Plastics) and consist of plastic trays fitted with a lid (Fig. 1). There are 60 shallow wells in the plate, each

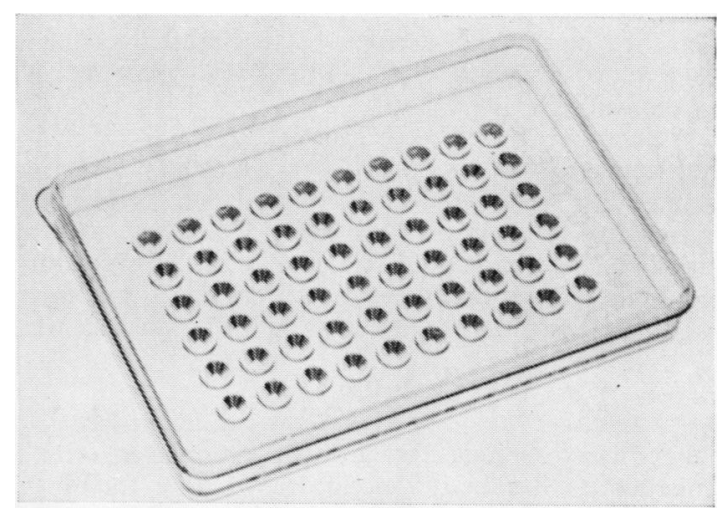

FIG. 1. The microplate used for the tissue culture studies. (Falcon Plastics.)

fitted with shelving sides, and capable of holding $15 \mu \mathrm{l}$ of culture medium. Monolayers are viewed using an inverted phase contrast microscope. These plates are continually used in tissue typing laboratories and were developed for the lymphocytotoxicity microtest by Terasaki (Terasaki, Vredevoe, and Mickey, 1967).

CULTURE OF KIDNEY CELLS A primary culture of human kidney cells was set up in a milk dilution bottle using a standard technique (Paul, 1960), in a growth medium of

${ }^{1}$ Supported in part by grants from the Felton Bequest and the National Health and Medical Research Council of Australia. 
$10 \%$ foetal calf serum, $10 \%$ heated autologous human serum, and $80 \%$ medium 199. After five days the cells were washed in balanced salt solution, trypsinized with $0.25 \%$ trypsin for 15 minutes, and then lightly centrifuged. The cells were then made up to $50,000 / \mathrm{ml}$ concentration and added to the wells with a Hamilton dispensing syringe, 500 cells in $10 \mu \mathrm{l}$ being added to each well. It was found that 500 cells was the optimal number; if less, a 'poor' monolayer resulted and if more, the monolayer became too thick and frequent changes of growth medium were required. The plates were placed in a moist airtight container with carbon dioxide to a concentration of $5 \% \mathrm{CO}_{2}$. The behaviour of cells in these wells resembled that seen in standard tissue culture vessels, ie, attachment and spreading within four hours and multiplication within 24 hours. The cells grew until the edges of the wells were reached and a good monolayer resulted (Fig. 2). After this there was little apparent growth but the monolayer persisted for another 21 days.

CULTURE OF SKIN FIBROBLASTS A primary culture of skin (human) fibroblasts was made using the technique of Harnden (1960). After 10 days cells were grown in a milk dilution bottle and finally transferred to the microplates. These cells behaved similarly to the kidney cells.

CHANGE OF GROWTH MEDIUM After cells have attached and spread, the medium may be changed simply by withdrawing with a fine pipette. The cells do not become detached during this manoeuvre. The fresh medium is then added by gently directing the flow against the side of the wall.

REUTILization OF Plates After use the plates were soaked in Pyroneg solution, washed in warm water, and rinsed five times in distilled water. They were then air dried and sterilized by gamma irradiation. Fresh cultures could then be set up. It was found that good monolayers would still result after the plates had been washed twice.

\section{COMMENT}

The microtechnique for growing monolayer cells in microplates has been described. We have found this technique to be suitable for the growth of skin fibroblasts and kidney cultures for periods of up to three weeks. We have also successfully used these cultures for cytotoxicity testing of antisera against monolayer cultures. The monolayers can easily be viewed and photographed using an inverted microscope with a phase contrast attachment. The advantages of this technique

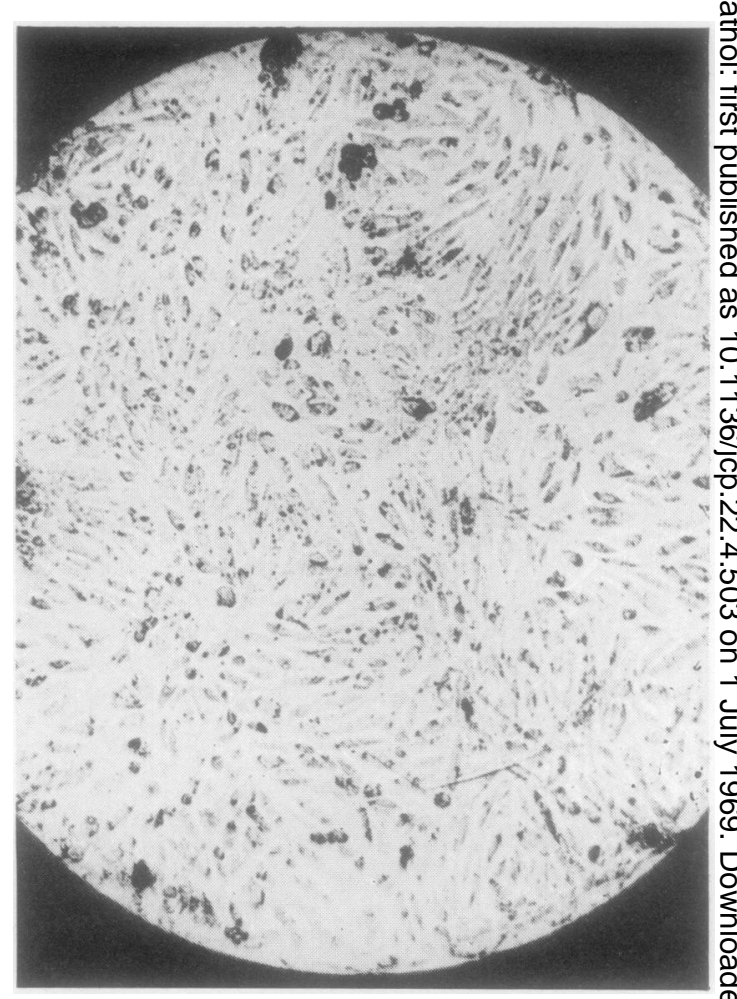

FIG. 2. Kidney epithelial cells are demonstrated in one of the wells of the microplate. $\times 90$.

are that large numbers of tests may be done using few reagents and cells: we use only 30,000 cells for 60 tests. The plates are easy to handle and routine tissue culture. work, such as changes in growth medium, can be per-응 formed in minutes. In addition the plates may be reutilized several times.

The photographs were taken by Mr Leslie Kont and Misso Leona Monarch, Department of Surgery, University of Melbourne.

\section{REFERENCES}

Harnden, D. G. (1960). Brit. J. exp. Path., 41, 31.

Terasaki, P. I., Vredevoe, D. L., and Mickey, M. R. (1967). Transplantation, 5, 1057.

Paul, J. (1960). Cell and Tissue Culture, 2nd ed., p. 176. Livingstone, $\omega$ Edinburgh and London. 